\title{
MATERIAL REMOVAL RATE AND SURFACE ROUGHNESS ON GRINDING OF DUCTILE CAST IRON USING MINIMUM QUANTITY LUBRICATION
}

\author{
M.M. Rahman ${ }^{1,2 *}$ and K. Kadirgama ${ }^{1}$ \\ ${ }^{1}$ Faculty of Mechanical Engineering, Universiti Malaysia Pahang \\ 26600 Pekan, Kuantan, Pahang, Malaysia \\ *Email: mustafizur@ump.edu.my \\ Phone: +6094246239; Fax: +6094246222 \\ ${ }^{2}$ Automotive Engineering Centre \\ Universiti Malaysia Pahang, 26600 Pekan, Pahang, Malaysia
}

\begin{abstract}
A promising alternative to conventional fluid coolant application is minimum quantity lubrication (MQL). Despite much research, there have been few investigations about the influence of MQL parameters on the process results, such as oil flow rate, workpiece speed and depth of cut. The objective of this project is to develop a mathematical model of the material removal rate and surface roughness on grinding of ductile cast iron using minimum quantity lubrication. The experiment was carried out according to the design of experiment principle, prepared based on central composite design. The experimental data was utilized to develop the mathematical model for first- and second-order models. The second order gives acceptable performance of the grinding. The result shows that the highest value of the grinding ratio is with single-pass MQL, and the lowest value is with multiple-pass conventional coolants. The model fit was adequate and acceptable for sustainable grinding using a $0.15 \%$ volume concentration of ethylene glycol. This paper quantifies the impact of water-based ethylene glycol on the surface quality achieved. It is concluded that the surface quality is most influenced by the depth of cut and table speed. It is recommended that future research is also conducted using another parameter such as the speed of the grinding wheel or the distance from the wheelworkpiece contact zone. Besides that, further research can be conducted using different nozzle angles and different types of grinding wheel to see how these affect the surface of the material.
\end{abstract}

Keywords: Minimum quantity lubrication; grinding; material removal rate; surface roughness; cast iron.

\section{INTRODUCTION}

Grinding is one of the material removal processes that is widely used in industry, and is used in order to get a better surface quality and very close tolerance, which is very strict for design components[1]. When the tools make contact with the workpiece surface, the heat rises in the latter [2]. Coolant is used to enhance the performance of grinding in terms of giving a better surface finish, reducing the temperature between the surface contacts and also cleaning the surface from the chips generated during the grinding process [3]. Large quantities of emulsion-based cooling fluids for machining are still widely used in the metal-working industry, generating high consumption and disposal costs and having an impact on the environment [4]. The increasing need for 
environmentally friendly production techniques and the rapid growth of cutting fluid disposal costs have led to demand for an alternative to the machining processes currently used. The introduction of Minimum Quantity Lubrication (MQL) makes use of a lubricant that replaces the conventional coolant in order to overcome the temperature and surface finish problems [5-8]. The use of coolant or cutting fluids is the most common strategy to solve this problem. However, the introduction of cutting fluids often produces air-borne mist, smoke and other particulates that affect the shop floor air quality. These products bring environmental, health and safety concerns. In addition, the cost of using cutting fluids is several times higher than the tool costs themselves. Environmental concerns have become increasingly important to productive processes, allied with their economic and technological aspects.

Green engineering is used to indicate environmental concerns in engineering. Green manufacturing is a subset of green engineering. Environmentally friendly machining is a part of green manufacturing. It is included in the concept of sustainable manufacturing, which considers economic and social concerns in addition to environmental concerns [9-12]. Environmentally friendly machining attempts to minimize the consumption of cutting fluid, cutting tools and energy. Green engineering is a modern manufacturing strategy, which has become popular as a sustainable development strategy in industrial processes and production. Dry machining and minimum quantity lubricant (MQL) machining have become the focus of attention of researchers and technicians in the field of machining as an alternative to traditional fluids[13, 14]. Silva, Bianchi [15] investigated the effects of grinding parameters on ABTN 4340 steel using the MQL technique. They found that the surface roughness, grinding force, diameter wear and residual stress improved with the use of the MQL system in the grinding process due to better lubrication of the grinding zone, and provided better slipping of grains at the contact zone. The concept of MQL is fundamentally different from that of flood coolant and this can be a large stumbling block to machinists who are new to MQL. MQL is an alternative intended to save money, while eliminating the mess, disposal and negative aspects of coolant use[11]. Ethylene glycol is one of the base fluids for nanofluid beside water, engine oil and cutting fluid. Ethylene glycol is also a chemical commonly used in many commercial and industrial applications including antifreeze and coolant. The major use of ethylene glycol is as a medium for convective heat transfer in, for example, car radiators, liquidcooled computers, chilled water air conditioning systems, and the like [16]. The response surface method [17] is a statistical method that uses quantitative data from appropriate experiments to determine and simultaneously solve multivariant equations. It is useful for analyzing and modeling problems to obtain a response of interest that is influenced by several variables [18]. The objective of this study is to evaluate the performance of MQL on surface grinding in terms of MRR and surface roughness and to develop a mathematical model based on the response surface method, and additionally to optimize the process parameters using RSM.

\section{METHODS AND MATERIALS}

The response surface method uses quantitative data from experimental results to determine and simultaneously solve multivariant equations. The main objective of RSM is to get the response of interest, which is the material removal rate for each different coolant condition. To find the value of the MRR, the mass difference of the workpiece 
and also the time taken is used. Table 1 shows the design of the central composite design method.

$$
\text { MRR }=\frac{\text { Massdifference }}{\text { Time aken }}
$$

Table 1. Central composite design method for MRR.

\begin{tabular}{ccc}
\hline Workpiece & Workpiece speed $(\mathrm{rpm})$ & Depth of cut $(\mu \mathrm{m})$ \\
\hline A & 25.2 & 2 \\
B & 25.2 & 4 \\
C & 25.2 & 6 \\
D & 12.5 & 2 \\
E & 12.5 & 4 \\
F & 12.5 & 6 \\
G & 8.7 & 2 \\
H & 8.7 & 4 \\
I & 8.7 & 6 \\
\hline
\end{tabular}

Response surface methodology explores the relationships between several explanatory variables and one or more response variables. The main idea of RSM is to use a set of designed experiments to obtain an optimal response. In this study, RSM is utilized for establishing the relations between the different grinding coolant parameters with a variety of machining criteria and exploring their effects on the response as the MRR. The response of surface roughness and material removal rate is described by Eq. (2):

$$
Y=C_{0}+\sum_{i=1}^{n} C_{i} x+\sum_{i=1}^{n} C_{i i} x_{i}{ }^{2}+\sum_{i=1}^{n-1} \sum_{j=2}^{n} C_{i j} x_{i j}
$$

where $Y$ is the corresponding response, SR or MRR, yielded by the various grinding process variables, and $x i(1,2, \ldots \ldots, n)$ are coded levels of $\mathrm{n}$ quantitative process variables, while the terms $C_{0}, C_{i}, C_{i i}$ and $C_{i j}$ are the second-order regression coefficients. The second term under the summation sign of this polynomial equation is attributable to the linear effect, whereas the third term corresponds to the higher-order effects; the fourth term of the equation includes the interactive effects of the process parameters. In this research, the equation can be written as Eq. [19]:

$$
Y=C_{0}+C_{1} x_{1}+C_{2} x_{2}+C_{3} x_{1} x_{3}+C x_{2}^{1}+C x_{2}^{2}
$$

where $X_{1}$ and $X_{2}$, are the workpiece speed and depth of cut respectively.

\section{G-Ratio}

The G-ratio is the value of the material removal rate and the value of the tool wear. The workpiece material and the grinding wheel are important to find the G-ratio value. This value is shown as the interaction between the MRR and the tool wear. The higher the 
value of the G-ratio, the better the method of grinding. To find the value of the G-ratio, Eq. (4) is used.

$$
\mathrm{G}-\text { ratio }=\frac{\text { Material removal rate }}{\text { Tool wear }}
$$

\section{RESULTS AND DISCUSSION}

The material removal rate is the rate at which material is removed per unit time, and the unit is grams per second $(\mathrm{g} / \mathrm{s})$. The material removal rates for ethylene glycol with MQL and conventional coolant for the single-pass and multiple-pass grinding processes are represented in Table 2. The experiment was conducted nine times with various combinations of workpiece speed and depth of cut. A 5\% volume concentration of soluble oil coolant and a $15 \%$ volume concentration of ethylene glycol were used. It can be observed that the minimum MRR in single-pass grinding using the conventional coolant was $0.00370 \mathrm{~g} / \mathrm{s}$. However, the minimum material removal rate was $0.00420 \mathrm{~g} / \mathrm{s}$ for the ethylene glycol with the combination of the table speed and depth of cut. On the other hand, the maximum value is $0.01420 \mathrm{~g} / \mathrm{s}$ and $0.00910 \mathrm{~g} / \mathrm{s}$ for the conventional coolant and the ethylene glycol respectively. It is slightly different in multiple-pass grinding. The minimum MRR in multiple-pass grinding using a conventional coolant was $0.01560 \mathrm{~g} / \mathrm{s}$. However, the minimum MRR was $0.02090 \mathrm{~g} / \mathrm{s}$ for ethylene glycol. The result for multiple-pass grinding shows that the depth of cut affects the MRR value. Besides that, multiple-pass grinding also gives higher values of MRR than single-pass. This is because in multiple-pass the grinding wheel passes the specimen ten times.

Table 2. Material removal rate for each coolant in different grinding conditions.

\begin{tabular}{ccccccc}
\hline & & & \multicolumn{4}{c}{ Material removal rate $(\mathrm{g} / \mathrm{s})$} \\
\cline { 4 - 7 } Specimen & $\begin{array}{c}\text { Workpiece } \\
\text { speed } \\
(\mathrm{rpm})\end{array}$ & $\begin{array}{c}\text { Depth } \\
\text { of cut } \\
(\mu \mathrm{m})\end{array}$ & $\begin{array}{c}\text { Sonventional } \\
\text { coolants }\end{array}$ & $\begin{array}{c}\text { Ethylene } \\
\text { glycol } \\
\text { with } \\
\text { MQL }\end{array}$ & $\begin{array}{c}\text { Conventional } \\
\text { coolants }\end{array}$ & $\begin{array}{c}\text { Ethylene } \\
\text { glycol } \\
\text { with } \\
\text { MQL }\end{array}$ \\
\hline 1 & 8.7 & 2 & 0.00370 & 0.00530 & 0.04780 & 0.02670 \\
2 & 8.7 & 4 & 0.00970 & 0.00700 & 0.01560 & 0.02670 \\
3 & 8.7 & 6 & 0.01200 & 0.00720 & 0.04080 & 0.02400 \\
4 & 12.5 & 2 & 0.00400 & 0.00420 & 0.01750 & 0.02340 \\
5 & 12.5 & 4 & 0.00790 & 0.00700 & 0.02110 & 0.02630 \\
6 & 12.5 & 6 & 0.01200 & 0.00910 & 0.08250 & 0.03000 \\
7 & 25.2 & 2 & 0.00700 & 0.00530 & 0.06620 & 0.02090 \\
8 & 25.2 & 4 & 0.00900 & 0.00720 & 0.08190 & 0.02510 \\
9 & 25.2 & 6 & 0.01420 & 0.00700 & 0.15670 & 0.02901 \\
\hline
\end{tabular}

Figure 1 shows the comparison between the conventional coolant and ethylene glycol with MQL for single- and multiple-pass grinding processes. Multiple-pass gives a higher MRR value compared to the single-pass. The MRR is slightly lower when using ethylene glycol (MQL) but the MRR value is higher when using conventional 
coolant. This is due to the effect of the nanoparticles that lubricate the two surfaces that slide over each other. Besides that, RSM is used to obtain the performance measure for the response of interest that is the material removal rate from the surface of the material. Tables 3 and 4 show analysis of variance for conventional coolant and ethylene glycol respectively. The result shows the consistently good performance of the grinding machine with a significant $\mathrm{p}$-value of analysis of variance that is less than 0.05 , while the lack of fit is more than 0.05 and the R-square value is more than $90 \%$. This implies that the data is fit and adequate for further analysis and that all the parameters have significance for the grinding performance.

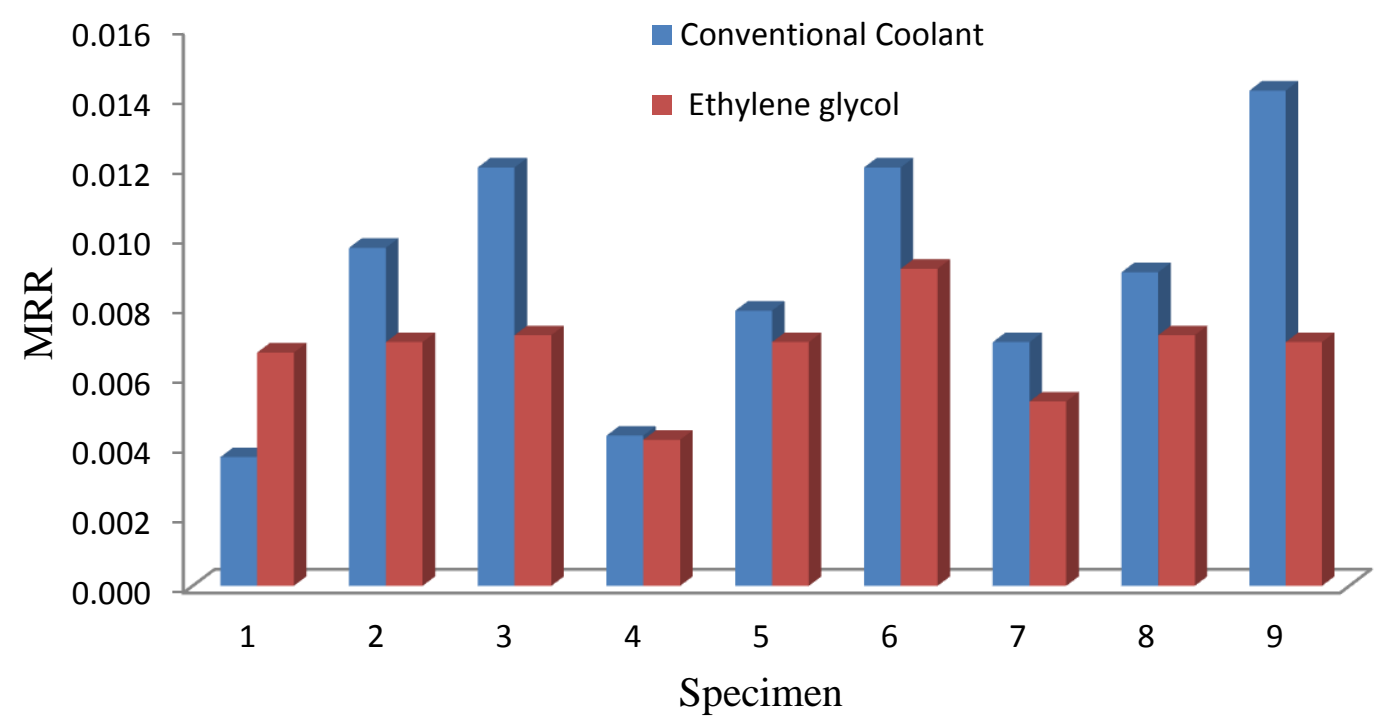

(a) single-pass grinding.

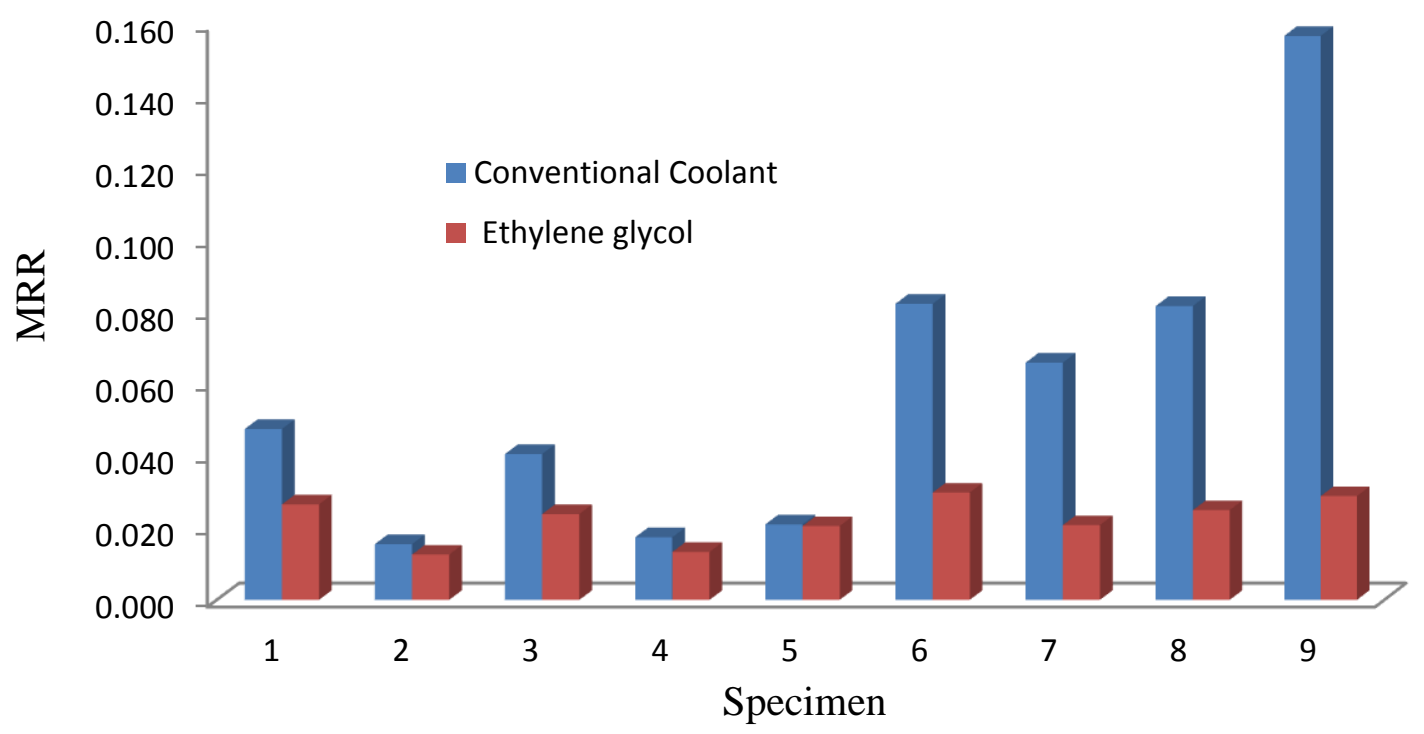

Figure 1. Materials removal rate for single- and multiple-pass grinding. 
Table 3. RSM for single-pass and multiple-pass with conventional coolant.

\begin{tabular}{lccccc}
\hline \multicolumn{1}{c}{ Term } & Coef & SE Coef & $\mathrm{T}$ & $\mathrm{P}$ & $\mathrm{R}^{2}$ \\
\hline Constant & 0.027384 & 0.000506 & 54.114 & 0.000 & $91.77 \%$ \\
Workpiece speed & 0.000027 & 0.000206 & 0.132 & 0.001 & \\
DOC & 0.001784 & 0.000210 & 8.493 & 0.000 & \\
Workpiece speed $\times$ & -0.001704 & 0.000526 & -3.240 & 0.004 & \\
Workpiece speed & & & & \\
DOC $\times$ DOC & -0.000227 & 0.000356 & -0.638 & 0.530 & \\
Workpiece speed $\times$ & -0.002593 & 0.000240 & -10.787 & 0.000 & \\
DOC & & & & 0.197 & \\
Lack of fit & & & & \\
\hline & 0.007428 & 0.000181 & 41.290 & 0.000 & $92.85 \%$ \\
Constant & 0.000217 & 0.000074 & 2.943 & 0.008 & \\
Workpiece speed & -0.0001859 & 0.000075 & -11.418 & 0.000 & \\
DOC & -0.0000784 & 0.000188 & -4.161 & 0.000 & \\
Workpiece speed $\times$ & & & & \\
Workpiece speed & -0.000289 & 0.000128 & $-2 . .266$ & 0.034 & \\
DOC $\times$ DOC & -0.001626 & 0.000086 & -18.886 & 0.000 & \\
Workpiece speed $\times$ & & & & \\
DOC & & & & 0.115 & \\
Lack of fit & & & & &
\end{tabular}

Table 4. RSM for single-pass and multiple-pass of ethylene glycol.

\begin{tabular}{lccccc}
\hline \multicolumn{1}{c}{ Term } & Coef & SE Coef & $\mathrm{T}$ & $\mathrm{P}$ & $\mathrm{R}^{2}$ \\
\hline Constant & -0.01529 & 0.000534 & -28.653 & 0.000 & 99.94 \\
Workpiece speed & -0.003331 & 0.000217 & -153.663 & 0.000 & $\%$ \\
DOC & 0.02055 & 0.000222 & 92.791 & 0.000 & \\
Workpiece speed $\times$ & 0.06449 & 0.000555 & 116.267 & 0.000 & \\
Workpiece speed & 0.02859 & 0.000375 & 76.141 & 0.000 & \\
DOC $\times$ DOC & -0.02398 & 0.000253 & -94.601 & 0.000 & \\
Workpiece speed $\times$ & & & 0.153 & \\
DOC & \multicolumn{5}{c}{ Multiple-pass } \\
Lack of fit & 0.007992 & 0.000196 & 40.842 & 0.000 & $98.65 \%$ \\
\hline Constant & 0.000378 & 0.000080 & 4.752 & 0.000 & \\
Workpiece speed & 0.003571 & 0.000081 & 43.951 & 0.000 & \\
DOC & 0.001496 & 0.000203 & 7.354 & 0.000 & \\
Workpiece speed $\times$ & 0.000138 & -1.323 & 0.200 & \\
Workpiece speed & -0.0000182 & 0.000 & \\
DOC $\times$ DOC & -0.0001301 & 0.000093 & -13.991 & 0.000 & \\
Workpiece speed $\times$ & & & 0.211 & \\
DOC & & & &
\end{tabular}


The adequacy of the second-order model is verified using the P-value of lack of fit. At a level of confidence of $95 \%$, the model is checked for this adequacy. Based on ANOVA analysis, the predictions of the material removal rate in both the single-pass and multiple-pass grinding process using ethylene glycol are presented in Tables 3 and 4 respectively. The model is adequate due to the fact that the P-values lack of fit is insignificant. The lack of fit values are 0.153 for single-pass grinding and 0.211 for multiple-pass, which is greater than 0.05. This implies that both models are fit and adequate for further analysis. The second-order equation used to predict the MRR in the single-pass and multiple-pass grinding process for ethylene glycol can be expressed as Eq. (5) and Eq. (6) respectively:

$$
\begin{aligned}
& M R R_{\text {Secondorde, } \text { sin } \text { glepass }}=-0.0159-0.03331 x_{1}+0.02055 x_{2}-0.02398 x_{1} x_{2} \\
& +0.006731 x_{1}^{2}+0.0005342 x_{2}^{2} \\
& M R R_{\text {Secondordemultipass }}=0.007992+0.000378 x_{1}+0.003571 x_{2}-0.001301 x_{1} x_{2} \\
& +0.113452 x_{2}^{1}-0.1234 x_{2}^{2}
\end{aligned}
$$

Table 5 lists the data of the experimental and predicted values of the MRR

\begin{tabular}{|c|c|c|c|c|c|c|c|}
\hline \multirow{3}{*}{$\begin{array}{l}\text { Specim } \\
\text { en }\end{array}$} & \multirow{3}{*}{$\begin{array}{l}\text { Depth } \\
\text { of cut } \\
(\mu \mathrm{M})\end{array}$} & \multicolumn{6}{|c|}{ Material removal rate $(\mathrm{G} / \mathrm{S})$} \\
\hline & & \multicolumn{3}{|c|}{ Single-pass } & \multicolumn{3}{|c|}{ Multiple-pass } \\
\hline & & $\begin{array}{c}\text { Experimen } \\
\text { tal }\end{array}$ & $\begin{array}{l}\text { Predictio } \\
n\end{array}$ & $\begin{array}{l}\text { Erro } \\
\text { r (\%) }\end{array}$ & $\begin{array}{l}\text { Experimen } \\
\text { tal }\end{array}$ & $\begin{array}{c}\text { Predictio } \\
n\end{array}$ & $\begin{array}{l}\text { Error } \\
(\%)\end{array}$ \\
\hline 1 & 2 & 0.0091 & 0.0090 & 1.10 & 0.0254 & 0.0260 & 2.36 \\
\hline 2 & 4 & 0.0071 & 0.0070 & 1.41 & 0.0261 & 0.0260 & 0.38 \\
\hline 3 & 6 & 0.0040 & 0.0040 & 0.00 & 0.0250 & 0.0250 & 0.00 \\
\hline 4 & 2 & 0.0070 & 0.0070 & 0.00 & 0.0231 & 0.0230 & 0.43 \\
\hline 5 & 4 & 0.0065 & 0.0070 & 7.69 & 0.0273 & 0.0270 & 1.10 \\
\hline 6 & 6 & 0.0072 & 0.0070 & 2.78 & 0.0293 & 0.0300 & 2.39 \\
\hline 7 & 2 & 0.0052 & 0.0050 & 3.85 & 0.0227 & 0.0210 & 7.49 \\
\hline 8 & 4 & 0.0062 & 0.0061 & 1.61 & 0.0250 & 0.0260 & 4.00 \\
\hline 9 & 6 & 0.0071 & 0.0070 & 1.41 & 0.0320 & 0.0300 & 6.25 \\
\hline
\end{tabular}
model. The predicted and experimental values are closely related. This is because the percent error between the predicted and experimental values is less than $7.5 \%$.

Table 5. Differentiation between experimental and predicted values of MRR.

\section{Surface Roughness}

Surface roughness was used to determine the quality of the workpiece characteristics, such as the minimum tolerance, lubricant effectiveness and the component life. Table 6 shows the surface roughness under different coolants and types of grinding. The reading was taken three times and the average is calculated. A good and better quality surface is with arithmetic mean roughness, Ra, below $0.8 \mu \mathrm{m}$ (Rahman et al., 2014). Different types of grinding combined with different coolant flow rates and different types of 
coolant lead to good results where all the outcomes or surface roughness values are less than $0.8 \mu \mathrm{m}$.

Table 6. Surface roughness for each coolant and different types of grinding.

\begin{tabular}{|c|c|c|c|c|c|c|}
\hline \multirow[b]{3}{*}{ Specimen } & \multirow{3}{*}{$\begin{array}{l}\text { Workpiece } \\
\text { speed } \\
\text { (rpm) }\end{array}$} & \multirow{3}{*}{$\begin{array}{l}\text { Depth } \\
\text { of cut } \\
(\mu \mathrm{m})\end{array}$} & \multicolumn{4}{|c|}{ Surface roughness $(\mu \mathrm{m})$} \\
\hline & & & \multicolumn{2}{|c|}{ Single-pass } & \multicolumn{2}{|c|}{ Multiple-pass } \\
\hline & & & $\begin{array}{l}\text { Conventional } \\
\text { coolants }\end{array}$ & $\begin{array}{c}\text { Ethylene } \\
\text { glycol } \\
\text { (MQL) }\end{array}$ & $\begin{array}{l}\text { Conventional } \\
\text { coolants }\end{array}$ & $\begin{array}{c}\text { Ethylene } \\
\text { glycol } \\
\text { (MQL) }\end{array}$ \\
\hline 1 & 8.7 & 2 & 0.21400 & 0.44100 & 0.29110 & 0.37900 \\
\hline 2 & 8.7 & 4 & 0.16430 & 0.35900 & 0.33730 & 0.421100 \\
\hline 3 & 8.7 & 6 & 0.25760 & 0.43200 & 0.54720 & 0.53300 \\
\hline 4 & 12.5 & 2 & 0.24300 & 0.46300 & 0.38300 & 0.39800 \\
\hline 5 & 12.5 & 4 & 0.17300 & 0.33300 & 0.41820 & 0.36100 \\
\hline 6 & 12.5 & 6 & 0.23400 & 0.34700 & 0.53200 & 0.40600 \\
\hline 7 & 25.2 & 2 & 0.35600 & 0.55000 & 0.36720 & 0.41100 \\
\hline 8 & 25.2 & 4 & 0.25300 & 0.41700 & 0.38420 & 0.37700 \\
\hline 9 & 25.2 & 6 & 0.31900 & 0.41900 & 0.48250 & 0.40800 \\
\hline
\end{tabular}

The RSM for surface roughness shows the good performance of the grinding machine with a significant $\mathrm{p}$-value of analysis of variance that is below 0.05 , with lack of fit more than 0.005 and the R-square value more than $90 \%$. This implies that all the data is fit and adequate. This shows that all the parameters have significance for the grinding performance and surface roughness. The second-order linear equations used to predict the surface roughness in the single- and multiple-pass grinding processes of ethylene glycol are Eq. (7) and Eq. [19] respectively:

$$
\begin{aligned}
& S R_{\text {Firstorder }, \text { sin } \text { glepass }}=0.28592-0.02428 x_{1}-0.04041 x_{2}+0.03042 x_{1} x_{2} \\
& +0.04762 x_{2}^{1}+0.1053 x_{2}^{2} \\
& S R_{\text {Firstorder,multipass }}=0.36273+0.01456 x_{1}+0.03681 x_{2}+0.03940 x_{1} x_{2} \\
& +0.135 x_{2}^{1}+0.023 x_{2}^{2}
\end{aligned}
$$

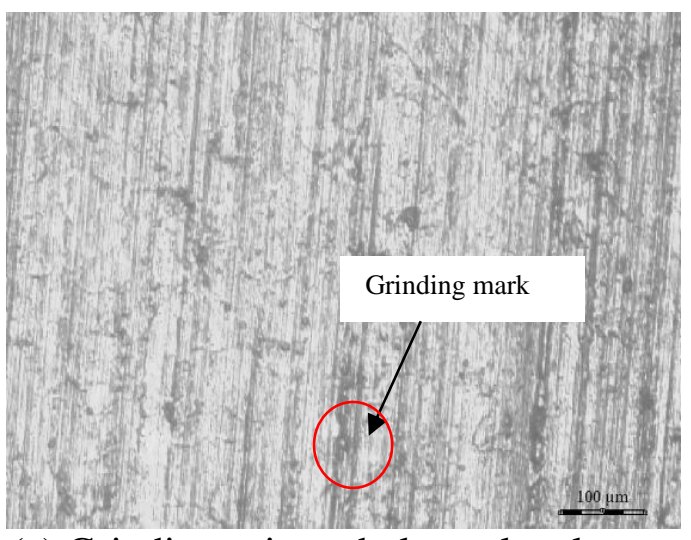

(a) Grinding using ethylene glycol.

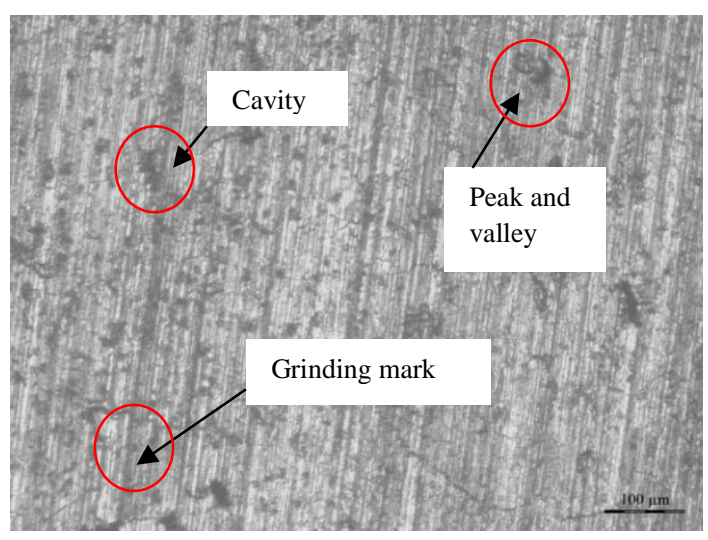

(b) Grinding using conventional coolant.

Figure 2. Scanning 2D microscope. 
Table 7 lists the experimental and predicted results for surface roughness. The predicted and experimental values are closely related. The error between the predicted and experimental results is within $10 \%$, which is reasonable and acceptable. Figure 2 shows the surfaces of the specimens for ethylene glycol and conventional coolant. No cavities, peaks or valleys are seen on grinding using ethylene glycol. This shows that ethylene glycol removed the heat and reduced friction better than the conventional coolant.

Table 7. Differentiation between experimental and predicted results for surface roughness.

\begin{tabular}{cccccccc}
\hline & & \multicolumn{6}{c}{ Surface roughness $(\mathrm{Ra}), \mu \mathrm{m}$} \\
\cline { 3 - 8 } Specimen & $\begin{array}{c}\text { Depth of } \\
\text { cut }(\mu \mathrm{m})\end{array}$ & \multicolumn{5}{c}{ Single-pass } & \multicolumn{5}{c}{ Multiple-pass } \\
\cline { 3 - 8 } & & Experimental & Prediction & $\begin{array}{c}\text { Error } \\
(\%)\end{array}$ & Experimental & Prediction & $\begin{array}{c}\text { Error } \\
(\%)\end{array}$ \\
\hline 1 & 2 & 0.4410 & 0.4510 & 2.27 & 0.3790 & 0.3760 & 0.79 \\
2 & 4 & 0.3590 & 0.3680 & 2.51 & 0.4210 & 0.4130 & 1.90 \\
3 & 6 & 0.4320 & 0.4320 & 0.00 & 0.5330 & 0.5280 & 0.94 \\
4 & 2 & 0.4360 & 0.4600 & 5.50 & 0.3980 & 0.3890 & 2.26 \\
5 & 4 & 0.3330 & 0.3300 & 0.90 & 0.3610 & 0.3650 & 1.11 \\
6 & 6 & 0.3470 & 0.3470 & 0.00 & 0.4060 & 0.4200 & 3.45 \\
7 & 2 & 0.5500 & 0.5610 & 2.00 & 0.4110 & 0.3760 & 8.52 \\
8 & 4 & 0.4170 & 0.4160 & 0.24 & 0.3770 & 0.4130 & 9.55 \\
9 & 6 & 0.4190 & 0.4200 & 0.24 & 0.4080 & 0.4280 & 4.90 \\
\hline
\end{tabular}

\section{Tool Wear and G-Ratio}

The G-ratio is the value of material removal rate per value of tool wear. This value shows the interaction between the MRR and tool wear. The higher the value of the Gratio, the better the grinding method is. Tool wear occurs when there is metal-to-metal contact between the chip and workpiece, especially under very high stress at high temperature. This situation is further aggravated due to the existence of extreme stress and temperature gradients near the surface of the tool. For this experiment, the tool wear was measured. The measurement was taken three times. During grinding, cutting wheels remove material from the workpiece to achieve the required shape, dimension, and surface roughness. However, tool wear occurs during the grinding action and will ultimately result in the failure of the cutting wheel. When the tool wear reaches a certain level $(0.3 \mathrm{~mm})$, the tool has to be replaced to guarantee the desired cutting action. The tool wear was measured in mm using a Taylorsurf profilometer. Several readings were taken and the average was calculated. Table 8 illustrates the tool wear for ethylene glycol and conventional coolant. In industry, tool wear should be minimized to ensure a good quality finish, precision, and cost. It can be seen that the pattern of the wear increases as the depth of cut and table speed increase for multiple-pass grinding. The ethylene glycol reduces the wear by almost $50 \%$ compared to the conventional coolant. This is due to the ethylene glycol reducing the friction between the two contact surfaces. 
Table 8. Tool wear for each coolant and type of grinding.

\begin{tabular}{ccccccc}
\hline & & & \multicolumn{4}{c}{ Tool wear (cm) } \\
\cline { 5 - 7 } Specimen & $\begin{array}{c}\text { Workpiece } \\
\text { speed } \\
(\mathrm{rpm})\end{array}$ & $\begin{array}{c}\text { Depth } \\
\text { of cut } \\
(\mu \mathrm{m})\end{array}$ & $\begin{array}{c}\text { Conventional } \\
\text { coolants }\end{array}$ & $\begin{array}{c}\text { Ethylene } \\
\text { glycol } \\
(\mathrm{MQL})\end{array}$ & $\begin{array}{c}\text { Conventional } \\
\text { coolants }\end{array}$ & $\begin{array}{c}\text { Ethylene } \\
\text { glycol } \\
(\mathrm{MQL})\end{array}$ \\
\hline 1 & 8.7 & 2 & 0.10 & 0.05 & 0.10 & 0.05 \\
2 & 8.7 & 4 & 0.10 & 0.05 & 0.15 & 0.05 \\
3 & 8.7 & 6 & 0.15 & 0.05 & 0.15 & 0.05 \\
4 & 12.5 & 2 & 0.15 & 0.05 & 0.25 & 0.05 \\
5 & 12.5 & 4 & 0.15 & 0.10 & 0.30 & 0.10 \\
6 & 12.5 & 6 & 0.25 & 0.10 & 0.30 & 0.10 \\
7 & 25.2 & 2 & 0.25 & 0.10 & 0.35 & 0.15 \\
8 & 25.2 & 4 & 0.30 & 0.10 & 0.40 & 0.15 \\
9 & 25.2 & 6 & 0.35 & 0.15 & 0.45 & 0.20 \\
\hline
\end{tabular}

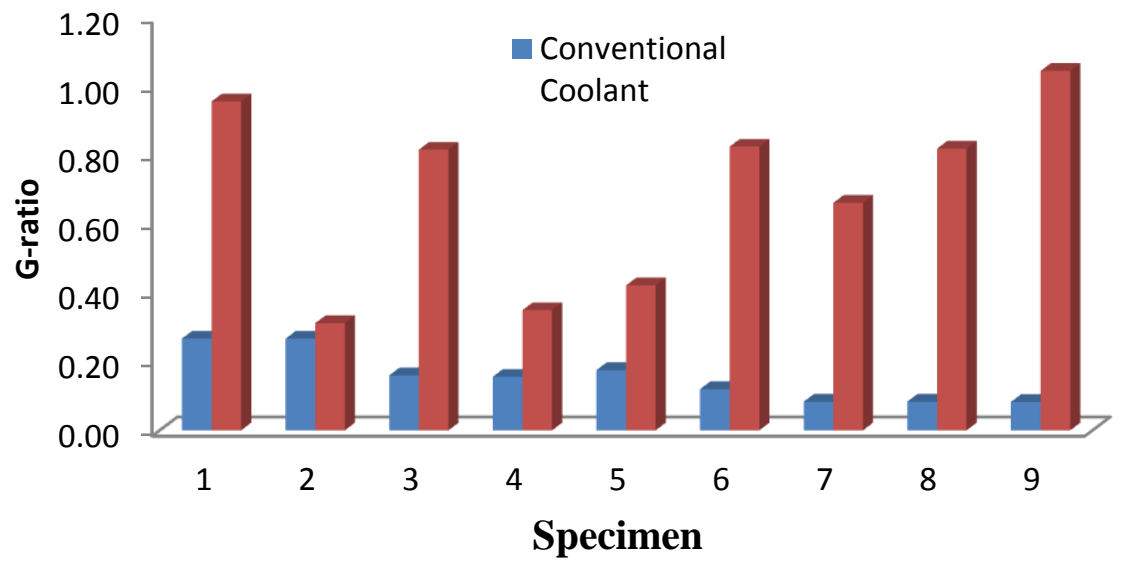

(a) Single-pass grinding

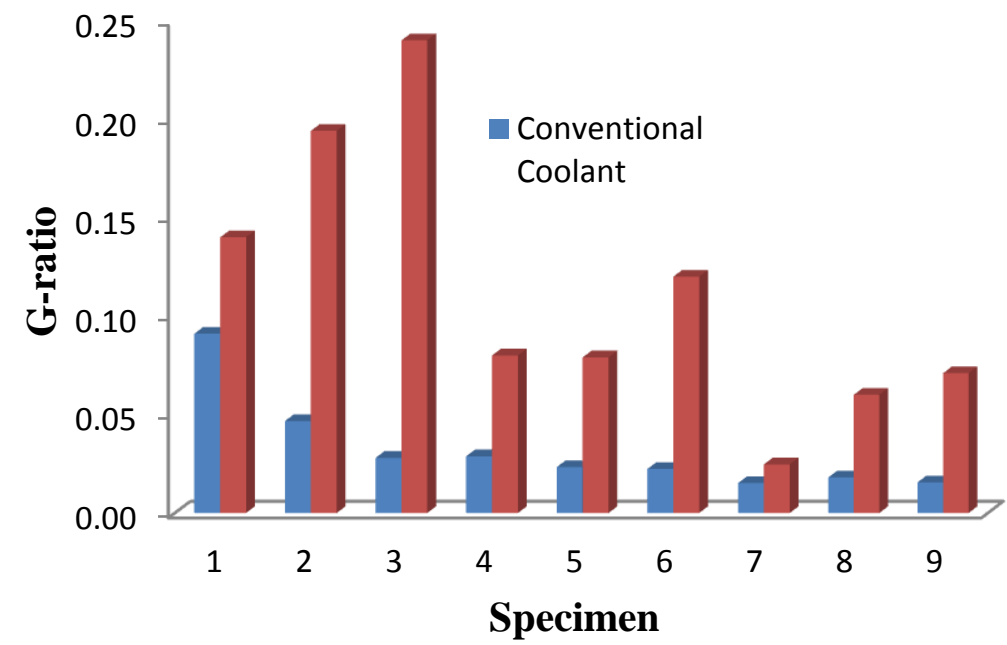

(b) Multiple-pass grinding

Figure 3. G-ratio of single- and multiple-pass grinding with different coolants. 
From Table 9 and Figure 3, it can be concluded that single-pass grinding with ethylene glycol has the highest value of G-ratio, followed by single-pass conventional coolant, multiple-pass ethylene glycol and lastly multiple-pass conventional coolant. As stated before, a higher value of G-ratio means that the method of grinding is better. It is concluded that the type of coolant as well as the type of grinding influence the G-ratio. Single-pass has a slightly higher G-ratio value compared to multiple-pass because single-pass only passes the specimen once, compared with 10 times with the multiplepass.

Table 9. G-ratio for each coolant and type of grinding.

\begin{tabular}{|c|c|c|c|c|c|c|}
\hline \multirow[b]{3}{*}{ Specimen } & \multirow{3}{*}{$\begin{array}{c}\text { Workpiece } \\
\text { speed } \\
\text { (rpm) }\end{array}$} & \multirow{3}{*}{$\begin{array}{l}\text { Depth } \\
\text { of cut } \\
(\mu \mathrm{m})\end{array}$} & \multicolumn{4}{|c|}{ Tool wear $(\mathrm{cm})$} \\
\hline & & & \multicolumn{2}{|c|}{ Single-pass } & \multicolumn{2}{|c|}{ Multiple-pass } \\
\hline & & & $\begin{array}{c}\text { Conventional } \\
\text { coolants }\end{array}$ & $\begin{array}{c}\text { Ethylene } \\
\text { glycol } \\
\text { (MQL) }\end{array}$ & $\begin{array}{c}\text { Conventional } \\
\text { coolants }\end{array}$ & $\begin{array}{c}\text { Ethylene } \\
\text { glycol } \\
\text { (MQL) }\end{array}$ \\
\hline 1 & 8.7 & 2 & 0.267 & 0.956 & 0.091 & 0.140 \\
\hline 2 & 8.7 & 4 & 0.267 & 0.312 & 0.047 & 0.194 \\
\hline 3 & 8.7 & 6 & 0.160 & 0.816 & 0.028 & 0.240 \\
\hline 4 & 12.5 & 2 & 0.156 & 0.350 & 0.029 & 0.080 \\
\hline 5 & 12.5 & 4 & 0.175 & 0.422 & 0.023 & 0.079 \\
\hline 6 & 12.5 & 6 & 0.120 & 0.825 & 0.022 & 0.120 \\
\hline 7 & 25.2 & 2 & 0.084 & 0.662 & 0.015 & 0.025 \\
\hline 8 & 25.2 & 4 & 0.084 & 0.819 & 0.018 & 0.060 \\
\hline 9 & 25.2 & 6 & 0.083 & 1.045 & 0.016 & 0.071 \\
\hline
\end{tabular}

\section{CONCLUSIONS}

The mathematical model of the material removal rate and surface roughness in the grinding of ductile cast iron using minimum quantity lubrication has been developed using the response surface method. The difference in performance of cast iron using ethylene glycol in terms of the material removal rate is insignificant compared to conventional coolant. In terms of tool wear, conventional coolant shows higher values than ethylene glycol. Besides that, between single-pass and multiple-pass, the multiplepass showed higher values of tool wear. This is because it has an effect on the G-ratio value. The higher the value of the G-ratio, the better the grinding method is. Therefore, the MRR should be maximized and at the same time the tool wear should be minimized for improved surface finish, cost and quality. So in terms of the G-ratio, ethylene glycol is more significant compared to conventional coolant. Besides that, the higher the oil flow rate, the better the surface of cast iron produced. In conclusion, MQL provides better performance and is also more environmentally friendly.

\section{ACKNOWLEDGMENTS}

The authors would like to acknowledgements Ministry of Education Malaysia and Universiti Malaysia Pahang for providing laboratory facilities and financial support under project no. RDU120310. 


\section{REFERENCES}

[1] Rahman MM, Kadirgama K, Ab Aziz AS. Artificial neural network modeling of grinding of ductile cast iron using water based $\mathrm{SiO} 2$ nanocoolant. International Journal of Automotive and Mechanical Engineering. 2014;9:1649-61.

[2] Shen B, Xiao G, Guo C, Malkin S, Shih AJ. Thermocouple fixation method for grinding temperature measurement. Journal of Manufacturing Science and Engineering. 2008;130:051014.

[3] Shaji S, Radhakrishnan V. Analysis of process parameters in surface grinding with graphite as lubricant based on the Taguchi method. Journal of Materials Processing Technology. 2003;141:51-9.

[4] Shen B, Shih AJ. Minimum quantity lubrication (MQL) grinding using vitrified CBN wheels. Trans NAMRI/SME. 2009;37:129-36.

[5] Tawakoli T, Hadad M, Sadeghi M, Daneshi A, Stöckert S, Rasifard A. An experimental investigation of the effects of workpiece and grinding parameters on minimum quantity lubrication-MQL grinding. International Journal of Machine Tools and Manufacture. 2009;49:924-32.

[6] Khan MAR, Rahman MM, Kadirgama K, Maleque MA, Ishak M. Prediction of surface roughness of Ti-6Al-4V in electrical discharge machining: A regression model. Journal of Mechanical Engineering and Sciences. 2011;1:16-24.

[7] Abu Bakar MH, Raja Abdullah RI, Md. Ali MA, Kasim MS, Sulaiman MA, Ahmad SSN, et al. Surface integrity of LM6 aluminum metal matrix composite when machined with high speed steel and uncoated carbide cutting tools. Journal of Mechanical Engineering and Sciences. 2014;6:854-62.

[8] Hamdan SH, Md Said AY, Biki JR. Surface finish when threading titaniumbased alloy under dry machining. Journal of Mechanical Engineering and Sciences. 2014;7:1062-9.

[9] Tawakoli T, Westkaemper E, Rabiey M, Rasifard A. Influence of the type of coolant lubricant in grinding with CBN tools. International Journal of Machine Tools and Manufacture. 2007;47:734-9.

[10] Najiha MS, Rahman MM, Kamal M, Yusoff AR, Kadirgama K. Minimum quantity lubricant flow analysis in end milling processes: A computational fluid dynamics approach. Journal of Mechanical Engineering and Sciences. 2012;3:340-5.

[11] Najiha MS, Rahman MM. A Computational Fluid Dynamics Analysis of Single and Three Nozzles Minimum Quantity Lubricant Flow for Milling. International Journal of Automotive and Mechanical Engineering. 2014;10:1891-900.

[12] Oliveira J, Alves SM. Development of environmentally friendly fluid for CBN grinding. CIRP Annals-Manufacturing Technology. 2006;55:343-6.

[13] Najiha MS, Rahman MM, Yusoff AR, Kadirgama K. Investigation of flow behavior in minimum quantity lubrication nozzle for end milling processes. International Journal of Automotive and Mechanical Engineering. 2012;6:76876.

[14] Puvanesan M, Rahman MM, Najiha MS, Kadirgama K. Experimental investigation of minimum quantity lubrication on tool wear in aluminum alloy 6061-t6 using different cutting tools. International Journal of Automotive and Mechanical Engineering. 2014;9:1538-49.

[15] Silva L, Bianchi E, Catai R, Fusse R, Franca T, Aguiar P. Study on the behavior of the minimum quantity lubricant-MQL technique under different lubricating 
and cooling conditions when grinding ABNT 4340 steel. Journal of the Brazilian Society of Mechanical Sciences and Engineering. 2005;27:192-9.

[16] Hollis JM, Lovas FJ, Jewell PR, Coudert L. Interstellar antifreeze: ethylene glycol. The Astrophysical Journal Letters. 2002;571:L59.

[17] Boersma BJ. A 6th order staggered compact finite difference method for the incompressible Navier-Stokes and scalar transport equations. Journal of Computational Physics. 2011;230:4940-54.

[18] Myers RH, Montgomery DC, Anderson-Cook CM. Response surface methodology: process and product optimization using designed experiments: John Wiley \& Sons; 2009. 